\title{
THE DEVELOPMENT OF ARMORED WAR VESSELS.-XIII.
}

\section{ARMOR PLATING IN THE UNITED STATES.}

\section{B Y J. H. MORR I S O N.}

AT the time of the appointment of the original Advisory Naval Board there were but two types of armor in use by the naval powers of Europe; the English fa-

Continued from Supplement No. 1663, page 310.

condition our navy had fallen in its type of vessels in bout sixteen years.

The first steel armored vessels of our modern navy voring the compound armor, having a hard steel face were the second-class battleships, the ill-fated "Maine"

from stem to stern of the vessel, having a thickness of 6 inches on the slope over the machinery and boiler spaces, and on the flat part of deck 3 inches thick. Protection to the hull along the waterline is obtained

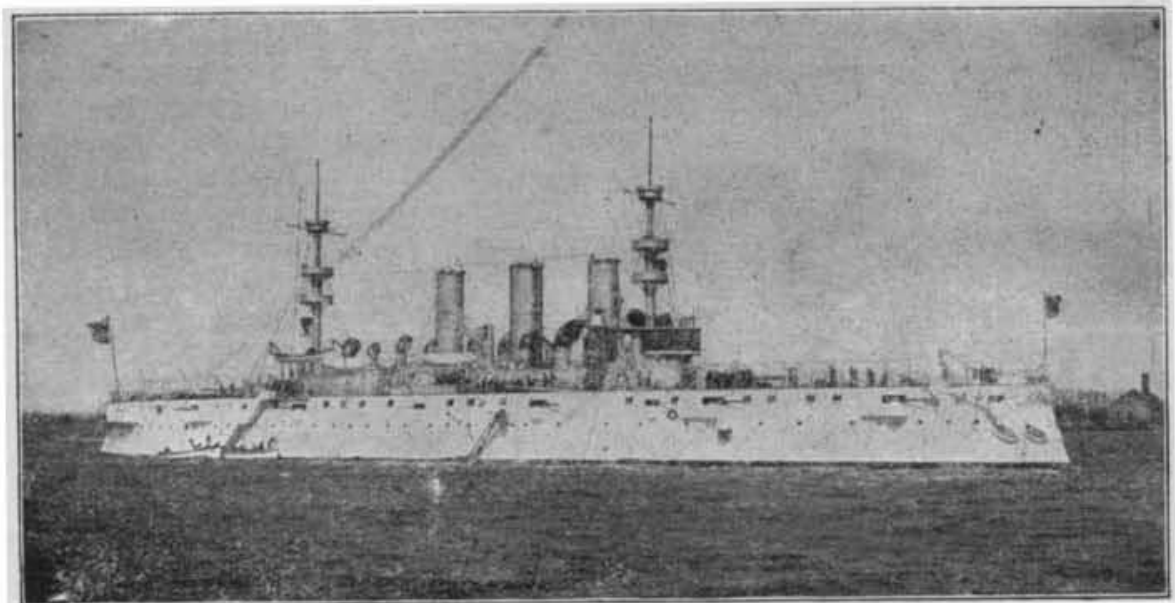

Copyright 1896 by W. H. Ra1n

ARMOREI) CRUISER "NEW YORK."

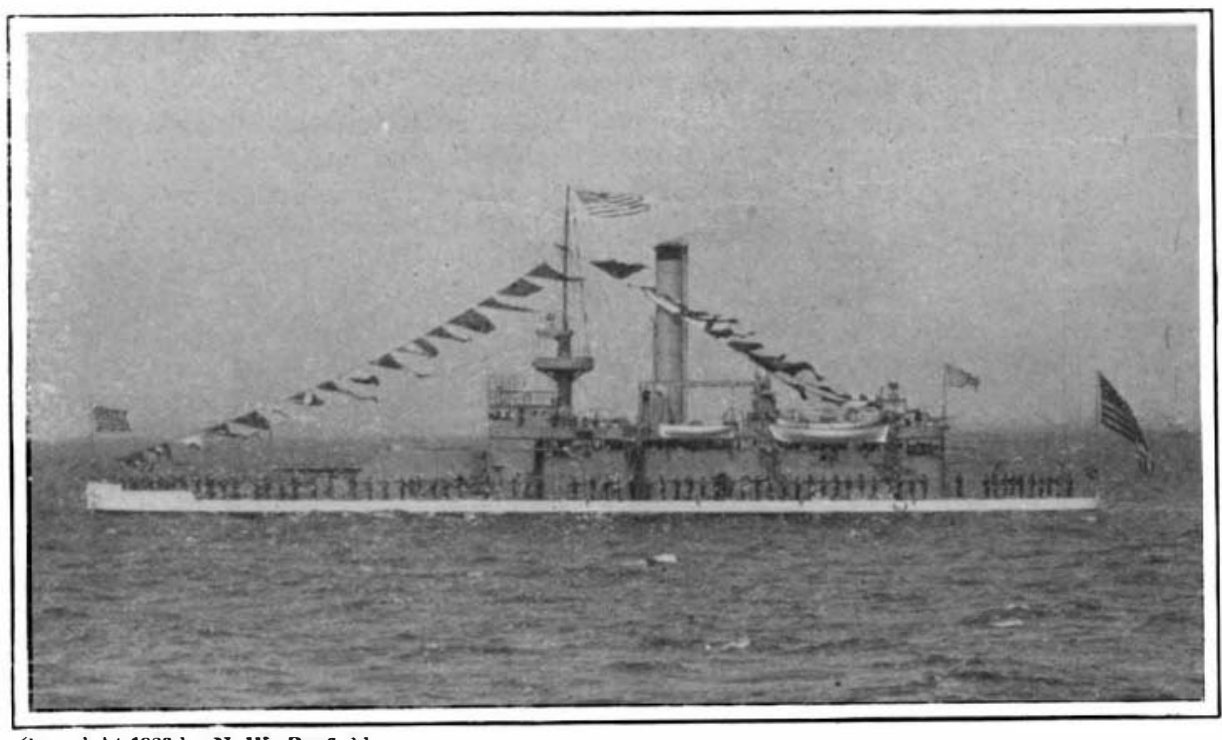

MONITOR "FLORIDA."

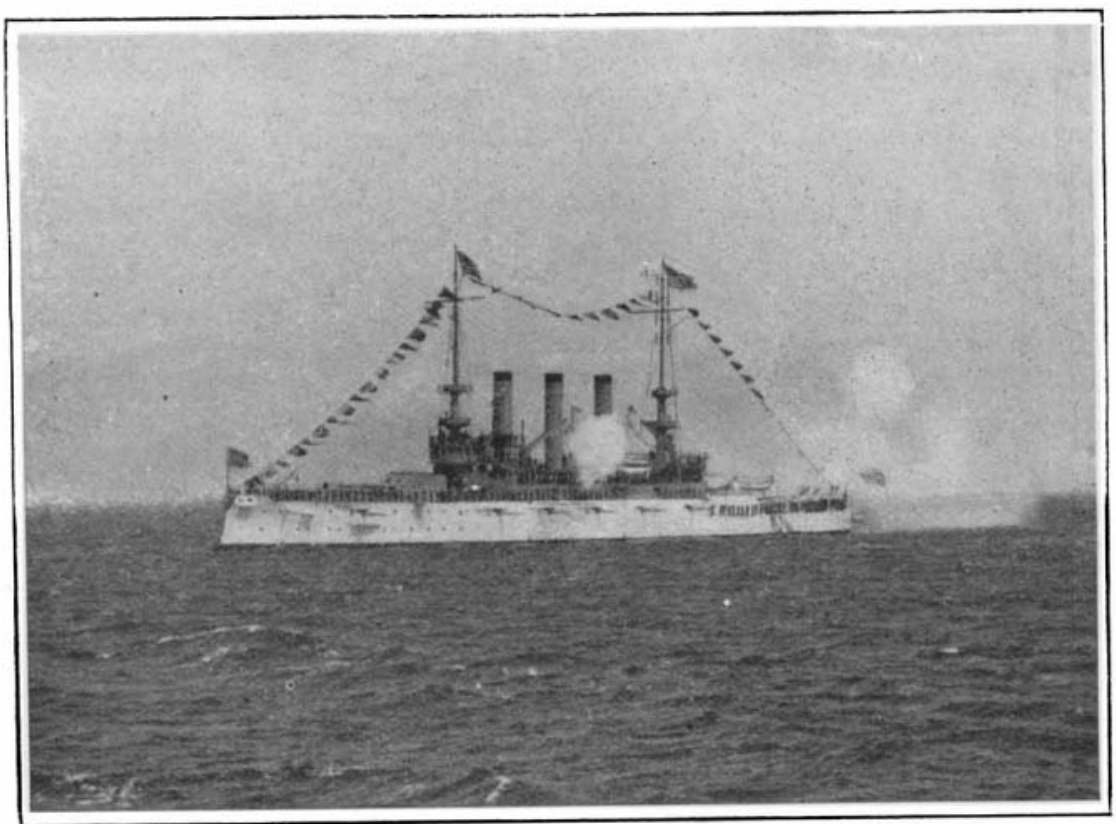

Copyright 1906 by N. W. Penficlit.

BATTLESHIP “MISSOURI."

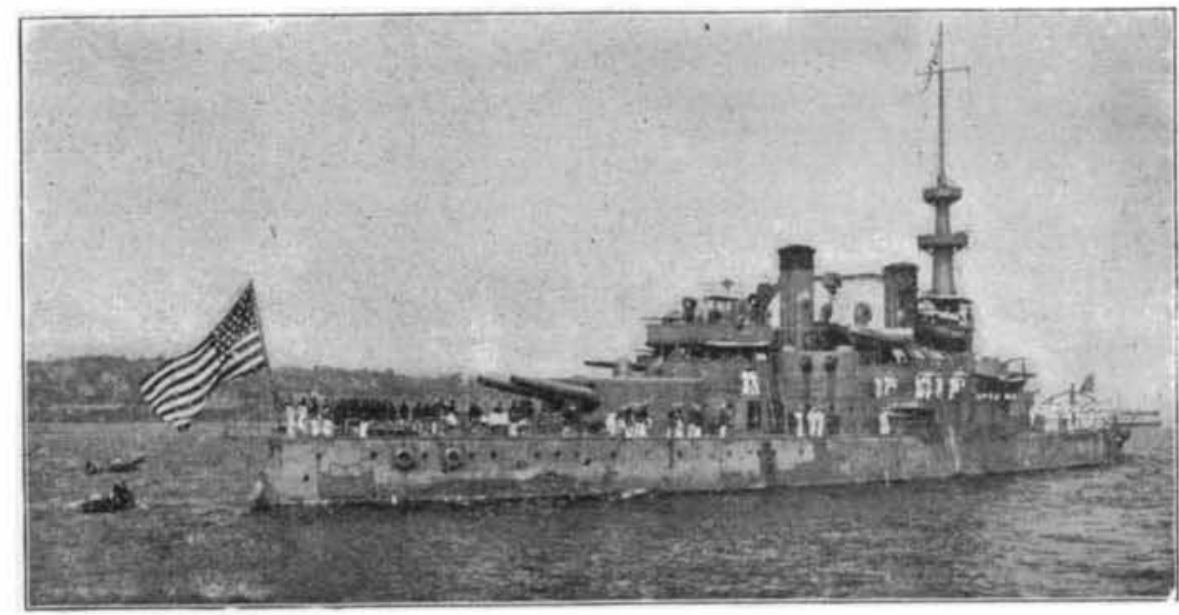

BATTLESHIP “OREGON."

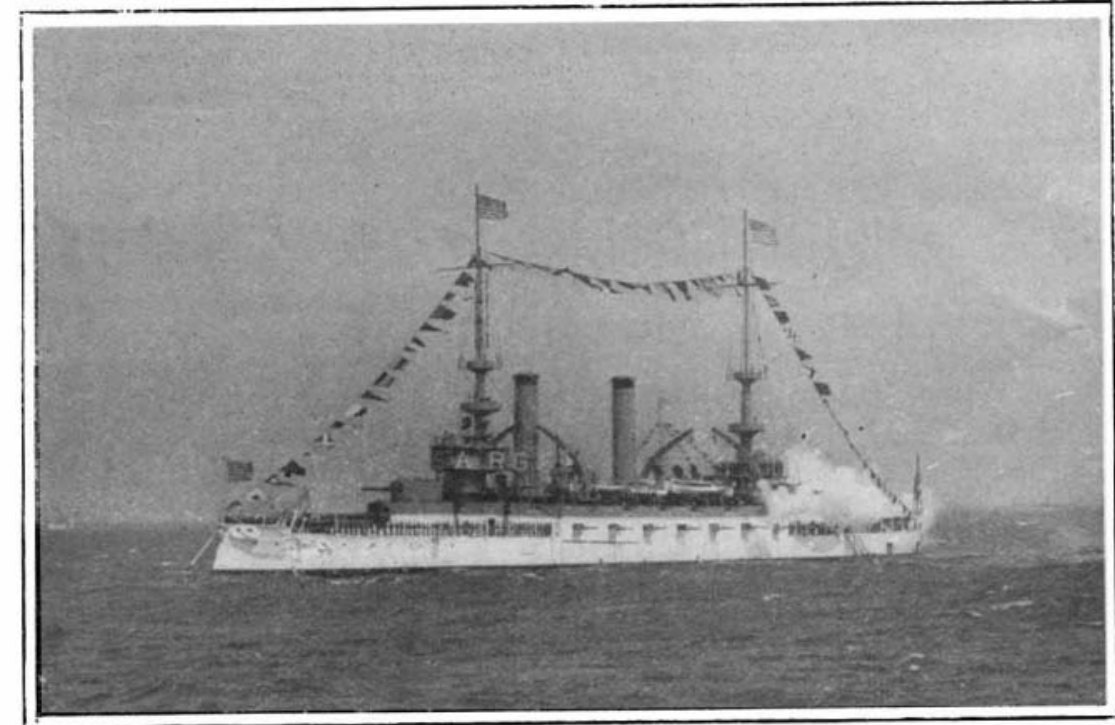

Copyright 1906 by N. W. Penfield.

BATTLESHIP “KEARSARGE."

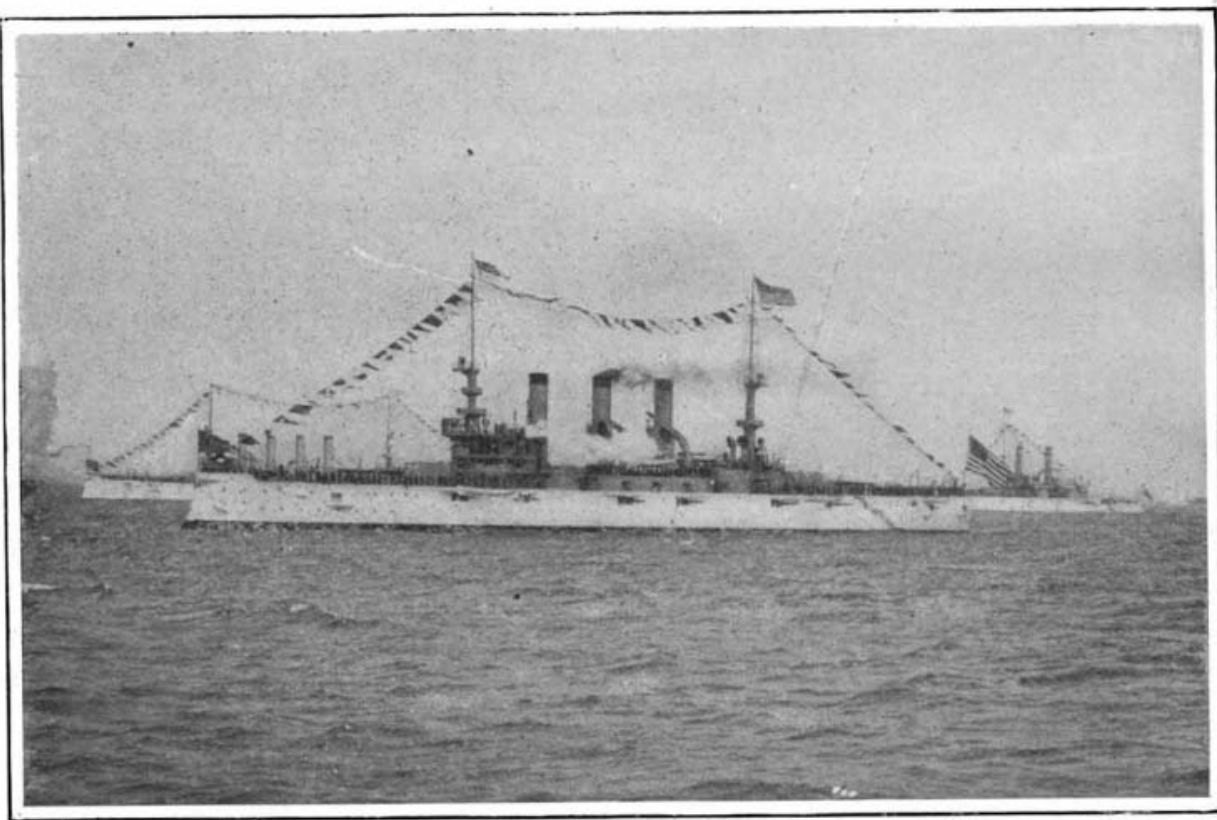

Copyright 1906 by N. W. Penfleld.

BATTLESHIP “LUUISIANA." welded to a tough iron back, the face being about onethird the thicliness of the whole plate. The French faored an all-steel plate, having a hardness and toughness designed to stop and break the projectile fired at it. The navy of Great Britain at this period had as their argest armored vessel the "Inflexible" completed in 1881, having a side armor "protecting the vital parts art also two others then building, the "Ajax" and the "Agamemnon," each having 18 inches side armor. The French navy had the "Admiral Baudin," the "Admiral Duperré," and the "Formidalıle," each having armor of the greatest thickness of $21 \%$ inches. They also had four frigalcs then building at the time, upon which armor of 18 inches in thickness was fitted. Comparisons may be unpopular, but this shows to what a low and the "Texas." The keel of the former was laid at the Brooklyn navy yard in October, 1888 , and her side armor was 12 inches thick, turrets 8 inches, and barbettes 12 inches. The "Texas" was built at the Norfolk navy yard, the keel being laid in June, 1889. The side and redoubt armor was 12 inches thick.

The pioneer first-class battleships were the "Indiana," the "Massachusetts," and the renowned "Oregon"; their keels being laid in May, June, and November, 1891, respectively. The side armor was 18 inches, the main turrets 15 inches, and the casemates 5 inches thick.

The amored cruisers "New York," whose keel was laid in September, 1890, and the "Broolilyn," whose keel was laid in August, 1893, were afforded protection to the hull by means of a steel protective deck running by means of an armor belt, 4 inches thick on the "New York" and 3 inches on the "Brooklyn," covering machinery and boiler spaces, and 4 feet above and 4 feet below the load waterline. The turret armor on the "New York" is $51 \%$ inches and barbette armor 10 and barbette armor 8 inches and 4 inch" is

The triple-screw protected cruisers "Columbia" of 1890 and the "Minneapolis" of 1891, the "Pirates," have each a protective deck extending the entire length of the vessel, and is made ul) of two courses of $1 \frac{1}{4}$-inch nickel steel, and on the slopes increased by an additional course of 11 inehes, making 4 inches; and for the remainder of the decli, $2 \%$ inches.

The protective deck was first carried the entire length of the vessel, dropping at the ends below the waterline, 
in our new navy, in the "Charleston" type of cruisers built in 1887 .

To see what changes have been made in the dimensions of the hulls and the armor of the several type of our armored naval vessels built within the las twenty years, we have but to refer to the table given velow.

The construction of the armored vessels of our modern navy did not progress toward completion with the same rapidity in the earlier vessels as they did at a later date, mainly on account of the armor plate not being ready for delivery to the Navy Department when the vessels under construction were ready to receive it. This class of work was altogether new to our shipbuilders at first, but they soon mastered the details. With the improved labor-saving machinery for such hea with the best builders of armored naval vessels in the world. The record shows that the "Maine" was launched in November, 1890, and the "Texas" in June, 1892 , and that the former was not placed in commis sion until September, 1895, and the latter in the month previous. The first-class battleships to re placed in commission were the "Indiana" in November, 1895, the "Massochusts" and the "Oregon" followed in June "Mnd July, 1896, respectively, and the "Iowa" in June, 1897. At this time the battleships "Kearsarge," "Kentucky," "Alabama," "Illinois," and "Wisconsin" were under construction. The other active vessels of the U. S. navy at this time were composed of thirteen of the unarmored protective cruiser type, three unprotected cruisers, four monitors, several gunboats, and five torpedo boats. The opening of the Spanish-American war fcilnd us with but five battleships, two armored cruisers, the six double-turret monitors, and

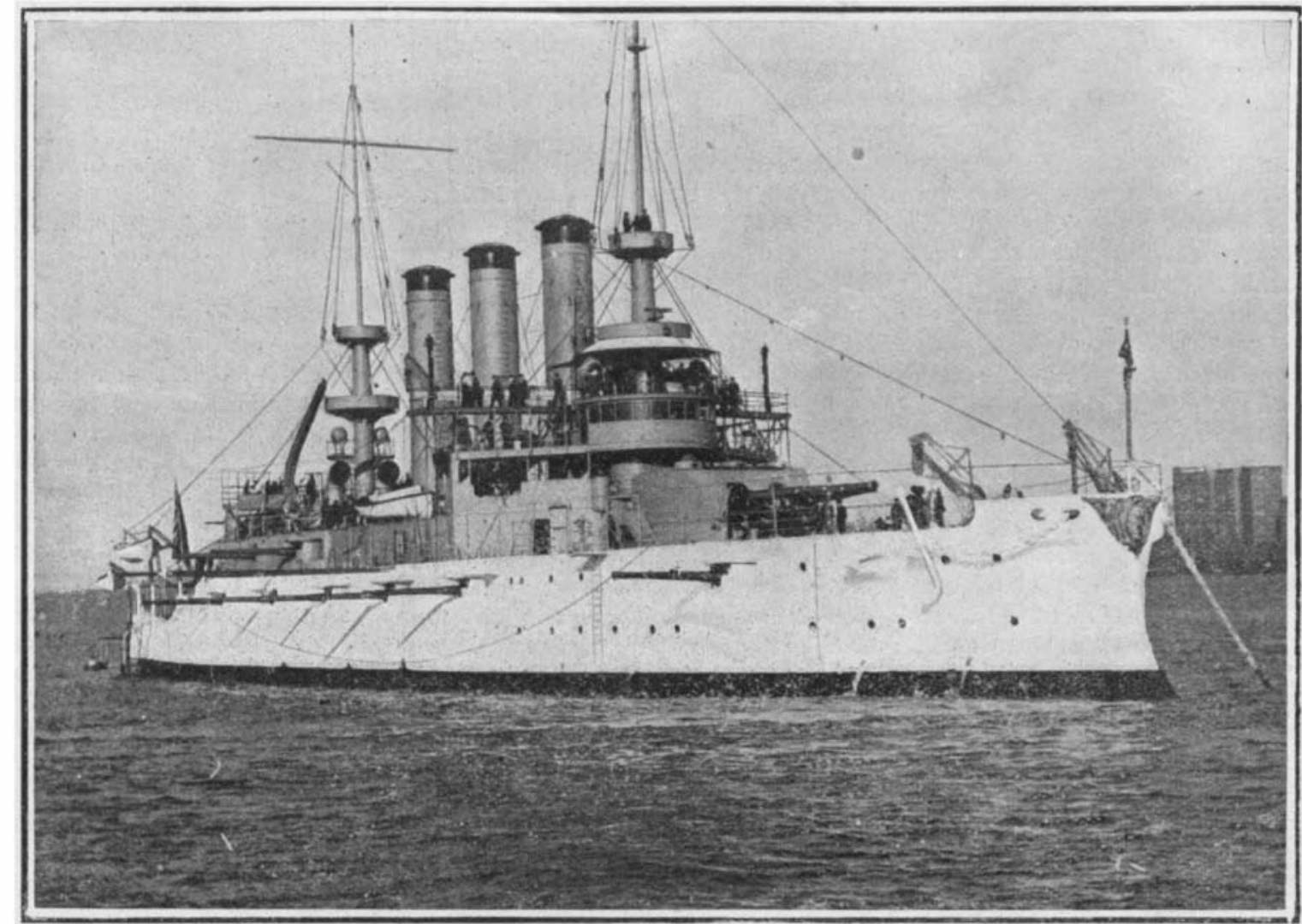

BATTLESHIP “OHI()."
It is since 1898 that the greatest development of our armored naval vessels has taken place. The marked

\begin{tabular}{|c|c|c|c|c|c|c|}
\hline \multirow{3}{*}{$\begin{array}{l}\text { "Texas," } 2 \mathrm{~d} \text { class } \ldots \ldots \ldots \\
\text { "Oregon," 1st class...... }\end{array}$} & \multicolumn{4}{|c|}{ BATTLFSHIPS. } & \multicolumn{2}{|l|}{ Armor. } \\
\hline & June, $\quad 1889$ & 301. & $4 \times 64$ & x 22.6 & 12 in. & 12 in. \\
\hline & Nov., 1891 & 348 & x 69.3 & $\times 24$ & $\begin{array}{c}18 \text { in. } \\
\text { Top } 16 \frac{1}{2} \text { in. }\end{array}$ & 15 and 6 \\
\hline “Alabama," 1st class..... & Dec.. 18.96 & 368 & x 72.2 & x 23.6 & $\begin{array}{l}\text { Bot. } 91 / 2 \text { in. } \\
\text { W. L. } 13 \% 4 \text { in. }\end{array}$ & \\
\hline “Kearsarge," 1st class... & June. 1896 & 368 & x 72.2 & $x 23.6$ & $161 / 2$ in., $91 / 2$ in., $133 / 4$ & 4 in. \\
\hline “Maine,” 1st class....... & Feb., 1899 & 388 & x 72.2 & x 23.6 & 11 and $71 \frac{1}{2}$ in. & 12 and $11 \mathrm{i}$ \\
\hline "Rhode Island," 1st class. & May, 1902 & 435 & x 76.2 & x 23.9 & 11 and 8 in. & $\begin{array}{l}81 / 2 \\
6\end{array}$ \\
\hline “Louisiana," 1st class.... & Feb., 1903 & 450 & x 76.10 & $0 \times 24.6$ & 11 and 9 in. & 12,8 and 6 \\
\hline
\end{tabular}

\section{ARMORED CRUISERS.}

Keel Laid.

"New York"

"Brooklyn"

"West Virginia"

Sept., 1890

Aug., 1893

Sept., 1901

June, 1903

Dimensions.
$380.6 \times 64.10 \times 23.3$
$400.6 \times 64.8 \times 24$
$502 \times 69.6 \times 24$
$502 \times 72.10 \times 25$

Turrets.

$51 / 2$ in.

$51 / 2$ in.

9,7 , and 5 in.

five of the old single-turret monitors as the armored advance that has been made since then in the conportion of our navy-not a very imposing fleet in struction of our naval guns has caused our naval connumbers nor in types.

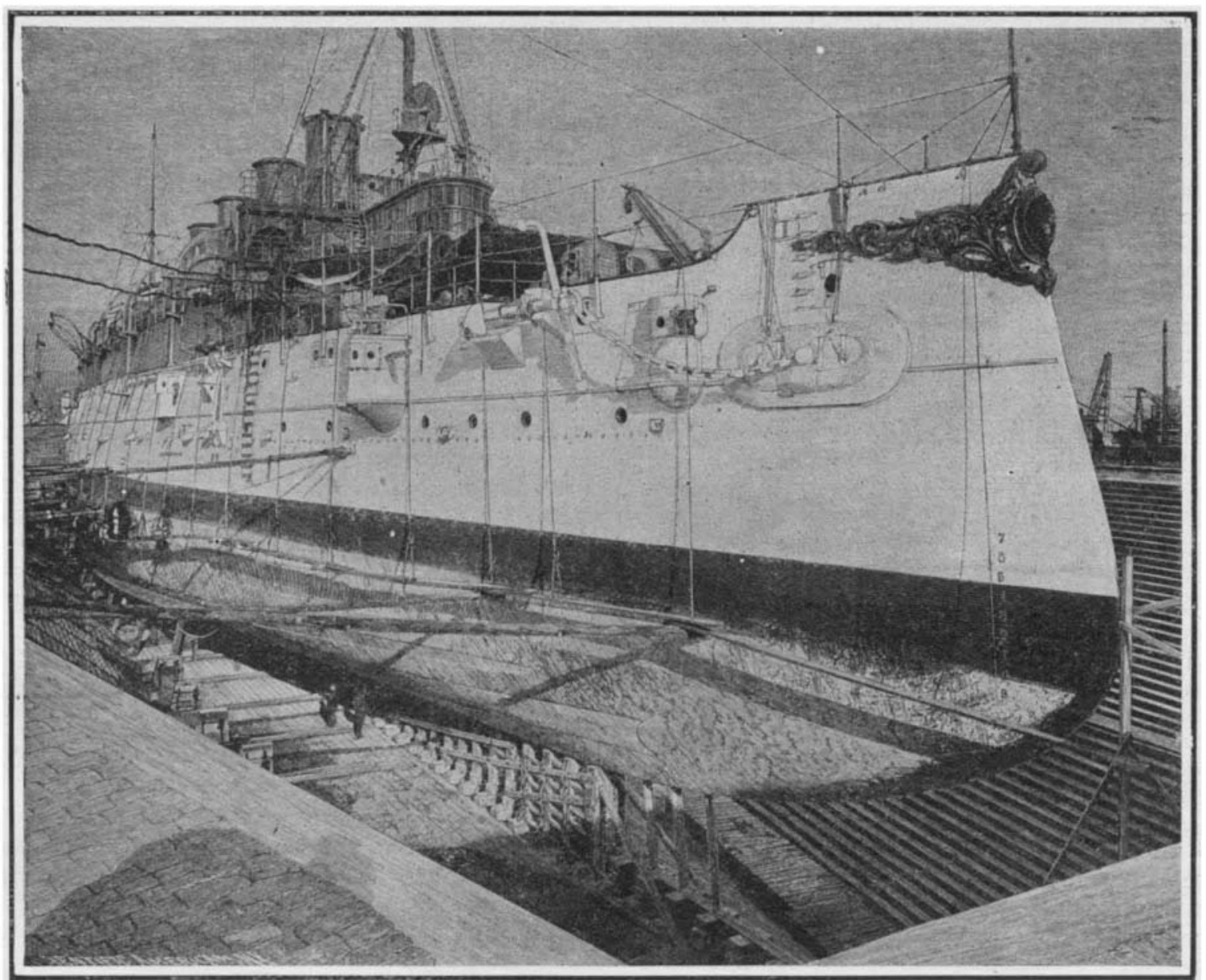

THE CRUISER "COLUMBIA" IN DRYDOCK.

greater defensive power in the later armored vessels. Then with the increased freeboard of the battleships, the extension of the protective deck, and the increased area of waterline armor belt, we have as high a clas? of fighting machine in our battleships as any nava power in the world. The latest armored cruisers have been so armored and protected as to be almost secondclass battleships. Since the close of the RussianJapanese war there have been different opinions entertained by expert naval constructors and the higher tertained hy exper naval the taligh the naval desisner during this war; but the general opinion scems to be at this stage of the discussion, that for the future a still larger vessel with increased speed and increased offensive gun power, for a battleship, than the most modern vessels now in commission is demanded.

If the practice of adding "system" after "system" in the new vessels continues, it will be but a short time the new vessels continues, it will be but a short time before the combined auxinheries will be greater than the capacity of the vessel to hold them. With all the electrical, pneumatic, hydraulic, and steam appliances for the protection and operation of the vessel at present, it may be difficult in the near future to find room for the machinery for the propulsion of the vessel, unless some design that occupies less room in a vessel than the triple-expansion engine and water tube boilers now demand. Possibly, the development of the turbine engine may solve the problem.

To note the marked advance that has been made in the size of our armored and protected vessels, we have but to take the second-class battleship "Texas," of 6,000 tons, with the "Vermont," a first-class battleship of 16,000 tons; and in the cruiser type, of the "Chicago," a protected cruiser only, of 5,000 tons, with the "Washington," an armored cruiser of 14,000 tons, al in the space of twenty years. That was making history very fast. There was a period of about fifteen tory very fast. There was a period of about fifteen years, ending in 1882 , when the Navy Department had,
it seems, no time to make any improvement of our naval vessels, only to build up a wooden vessel on an old keel, and call it "repairs." What a farce that was!

Since then the material conditions of the coun. try have largely developed, and a progressive spirit has been manifest in every move of the Navy Department in the construction of vessels, to obtain the best fleet of vessels of domestic material and construction that experience and science can suggest. They certainly have made marked progress in the short time they have types of vessels, and the naval constructors will no doubt give a good account of their skill in the future. Congress must take some of the responsibility for the dilatory rebuilding of our navy, in refusing to appropriate money for the specific object of constructans the ing the ron or steel vessels at it is doubtful if Congress so intended it at the time.

SPFED TRIALS OF ARMORED VESSELS OF THE UNITTI?

\begin{tabular}{|c|c|c|}
\hline & $\begin{array}{c}\text { STATES NAVY. } \\
\text { Battleships. }\end{array}$ & Knots, \\
\hline "Indiana" & & $\begin{array}{r}\text { Knots } \\
.15 .55\end{array}$ \\
\hline "Massachusetts" & & . 16.20 \\
\hline “Oregon" & & 16.79 \\
\hline "Iowa" & & 17.09 \\
\hline "Kearsarge" & & 16.816 \\
\hline "Kentucky" & & 16.897 \\
\hline "Alabama" & & 17.013 \\
\hline
\end{tabular}




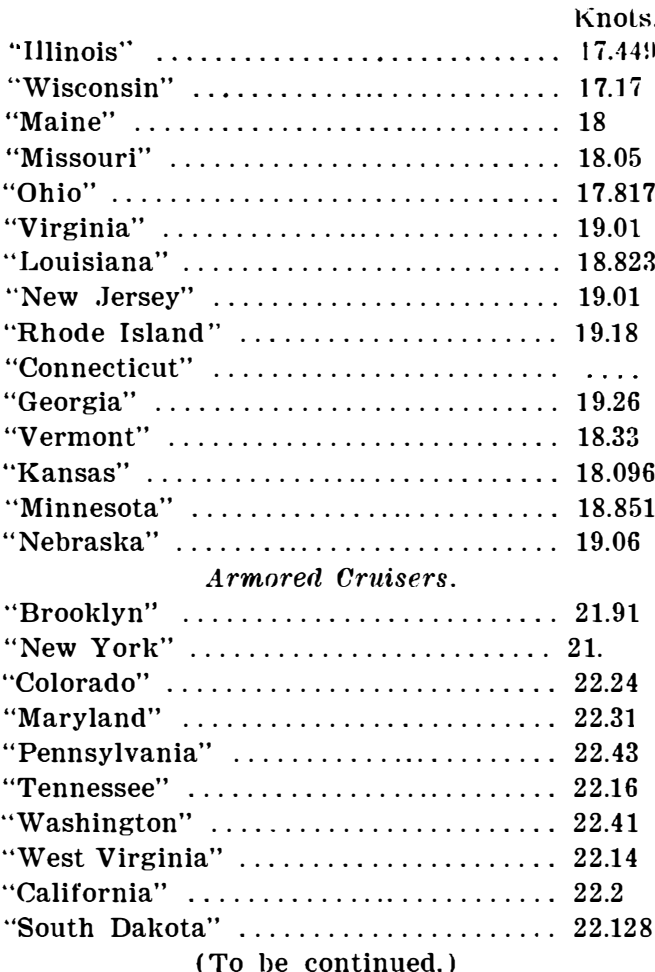

\section{THE LIMITS OF THE MIND AND THE LIMITS OF REALITY.}

Tinat which is small or large relatively to his own person, man regards as absolutely small or large. Man has a taste for ultimates in both directions. He will confidently, observes London Knowledge, criticising opponents of the "new" physics, describe earth air, fire and water as ultimate elements, and when these are replaced by more elemental bodies in his categories he confidently labels the newly found as atoms or "uncuttables." A later generation anatom izes the atom. Thereupon the electron is hailed as the ultimate of ultimates, further than which no one can go. Similarly in the other direction, we pass from The geocentric conceplion of the miverse to the helio
centric and from that to the idea of a finite and soli ary universe of which the Milky Way is the rim. Any notion of other such stellar systems is regarded as ludicrous. Within the past year, however, it has bee suggested that our stellar system is really the transient commingling of two systems, apparently quit independent in origin, which are drifting through and past each other, and to one of which our sun and ourselves belong.

Prof. Fournier has done much for this thesis through his lectures before bodies of scientific men Recognizing the ultimate invalidity of man's criteria both of space and time, he seeks to show how our manmeasured ideas have any basis at all. He seeks to show the difference between the limits of the mind and the limits of reality. We may conceive the world known to us as merely one of an indefinite number of varying magnitudes as to which we can predicate relative size only, absolute size not at all. Of course, the idea is not new, but only within this twentieth century could it so fruitfully have been worked out True, we could observe the analogy between the social and the individual organism and between the latter a society of many cells, and the single-celled creatures, which are societies of many molecules. Similarly we could conceive of the larger molecules as societies of many atoms; but there, having reached what we wer pleased to regard as an ultimate, we had to stop. Everyone is now familiar, however, with the analogy between an atom and a solar system. The attractive center or "sun" of the atom is a core of what we somewhat vaguely call "positive electricity," for gravitational attraction is substituted electric attraction, and for planets we have electrons or particles of "negative electricity" which revolve around the center and, relatively to their size, are quite as far apart as Jupiter and Mars from the earth:

If, now, any one should suggest, as Mr. Fournie does, that possibly the electrons or 'planets of the infra-world' are inhabited, we protest; but our ultimate argument is that these things are altogether too small for such possibilities, and thus the ultimate allueal is to msychology. Assuredly. however. noth ing is small or great, but thinling malkes it so and we have no more warrant for our conclusion than would an 'infra-man' for a similar sliepticism as to the life of bodies made up of what to him are solar systems and to us are atoms.

"Turn with Mr. Fournier to the conceltion of a supra-world, and we begin to realize that our ordi. nary notions have no more real validity than, let us say, would the notions of one of our blood corpuscles as to the nature of the stream in which it finds itself or the channels in which that stream runs. To such corpuscle itself is its own end, and it would be highly astonished on being told that it was really only one of countless billions which are regarded merely as subordinate parts of an organism, no less alive than itself the dimensions of which, relatively to the corpuscle, are perhaps as great as the dimensions of tie solar are perhaps as great as the dimensions of tine solar
system, or indeed the stellar system to ourselves. If the size and anatomy of man were revealed to one of his tiny constituent cells would they not applear as mereiy mechanical, insentient, and monstrous as the stellar heavens do to us, looking upon them from within?

"In the light of such considerations, many of our taken-for-granted notions are seen to be meaningless. Our solar system, with its planets and their planets or moons, may quite fairly be likened to a constituent atom of the mighty molecule or organism, perhaps, which we call the stellar universe; the number of such atoms or solar systems constituting our particular stellar system, say one hundred millions, is by no means incomparable with the number which must be contained in the smallest living organism known (as such) to us. The relative brevity of human life is an irrelevant consideration if once we disabuse ourselves of the uncritical metaphysical assumptions which are so earnestly credited by those who flatter themselves that they are superior to all 'mere metaphysics.' To regard the secular movements of the stars as absolutely 'long' is as unwarrantable as to regard the year of an electron-its period of rotation within the atom-as absolutely short."

\section{$\begin{array}{llllllllllllllll}\text { I } & \text { E } & \mathbf{F} & \text { I } & \mathbf{R} & \text { A } & \mathbf{N} & \mathbf{D} & \mathbf{Y} & \mathrm{O} & \mathbf{H} & \mathrm{O} & \mathbf{U} & \mathbf{R} & \mathbf{T} & \mathbf{H} .\end{array}$}

\section{LACTIC SUBSTANCES THAT PROMOTE HEALTH.}

Tir interest of the scientific world was recently aroused by the work of Prof. Metschnikoff, of Paris, and connected with the Pasteur Institute, upon fermented lactic bodies, which were found to have a highly beneficial action upon the organism. Such bodies are formed by causing the fermentation of milk by the products of certain grains or plants com ing from the Caucasus or the Balkan regions. Prof. Metschnikoff's attention was called to the fact that the action of such products upon the system is powerfully antiseptic and tends to destroy certain microbes which act as poisons. He claims that their use will tend to restore health generally and even to lengthen life; while in certain diseases the action is powerful. But hitherto it has been almost impossible to procure these products on a practical scale. This want is now filled by the Carrion Laboratory, of Paris, which is now preparing them for general use. These two products are known as kefir and yohourth. What is lnown as kefir is the product of a special fermentation of milk. This fermentation is the work of certain micro-organisms whose observation is now carried on by different scientists, especially since the remarlsable therapeutic and hygienic properties of kefir were cstablished and promulgated first by Russian doctors and then in all countries. The microscope reveals in liefir two kinds of ferments which are especially important, a yeast principle known as saccharomyces kefir. whose characteristics are analogous to those of bee and the grape, and also a bacillus whose name, bacil lus caucasicus, has reference to its far-off origin. It is shown that neither of the germs which participate in the kefiric fermentation is alone capable of full fermentation. For this it is necessary that they act fermentation. For this it is necessary that they act
in concert. Again, the kefiric fermentation will be carin concert. Again, the kefiric fermentation will be carwhich are veritable parasites, enter into the field in an appreciable quantity.

Hence, there are two kinds of precautions to be taken, first to keep up the harmony between the micro-organisms which accomplish the fermentation, and second, to exclude the parasites. The precautions are more needed in our countries than in the regions where the kefir is a native. Fortunately, since Pasteur's discoveries, we have the means of realizing them everywhere. What is needed is to supply pure milk with the pure germs. The method of keeping the germs in the pure state is one which belongs to the domain of laboratory processes, and cannot be dwelt upon at present.

What is specially to be noticed is the destructive part played by kefir upon the microbes and microbian loisous in the digestive tube. Kefir, in fact, possesses the properties of a living organism, seeing that special micro-organisms abound in it. These are agents mentations. Hence its important hygienic and therapeutic properties which have been brought out by M. Metschnikoff. It is a known fact that in the intes M. Metschnikoff. It is a known fact that in the intes-
tine, even in healthy persons, and much more so in dyspeptics, dangerous microbes are abundant. These are dangerous because they may be introduced into the organism and thus infect it, and also because they produce soluble poisons, and these latter can pass into the blood more easily than microbes. This kind of poisoning, whose source is in the intestine, is not always traced to its real cause. The organism, healthy in appearance, is in reality undermined by healthy in appearance, is in reality undermined by considers that such deleterious in fluence shortens the neriod of youth, hastens decay, and abridges the natural longevity of man. By suppressing it we delay old age and death

But it may be asked how we may act upon the cavity of the intestines itself. Should we seek to accomplish this effect by antiseptic products, we find these to be poisons which are still more dangerous for us than for the microbes. The process which $M$. Metschnikoff points out is, on the contrary, inoffensive and simple. To the infinitely small bodies which harm us, we oppose others of the same kind which are not by any means harmful to us, but even useful to a certain extent, and are active antagonists to the former. Such are the micro-organisms of kefir. His observations and those of M. Rovighi show that under disapperance of the kefiric regime we find an actual poisoning of the organism due to intestinal fermentapoisoning of the organism due to intestinal fermenta-
tion. Thus the kefir acts as an antiseptic for the intestine, and besides is not a medicine but an aliment of the highest order.

Seeing that it is produced from milk, kefir contains the primitive elements of mill, and is thus a complete food. Moreover, the fermentive bodies and the soluble ferments which go to produce the kefiric fermentation operate upon the albuminoid matter of the milk and give precisely a part of the changes which are usually carried out by the ferments of the digestive tube. Thus the micro-organisms of kefir co-operate with the glands of the stomach and the intestine and lighten their task and complete their action. In this way, taking an equal duration, the digestion of kefir will be more nearly perfect than that of milk. To an equal degree of perfection, it will be more rapid. This is not simply a theory, but is a fact which has been proved experimentally by Profs. Gilbert and Chasse- vant, of Paris, after thorough tests. They administered kefir to animals, or milk on the other hand, and found that the former always remains a shorter time in the stomach. Thus we find the properties of kefir to be a great digestibility and a high nutritive value. Kefir has the physical and organoleptic qualities which are connected with the ferments contained in it. We may mention some of these properties, and we find that they change slightly as the fermentation goes en in the course of time. This body has an acid reaction, which is due to lactic acid, this latter being developed by the partial transformation of milk sugar. It is also somewhat gaseous or "sparkling." This is due to the carbonic acid gas which is given off by the fermentation. It has somewhat the appearance of cream, owing to the state of the albuminoid matter, this being in the form of a very fine precipitate which, when the whole is shaken up, remains in suspension for some time. When allowed to stand for a long time the kefir separates into two layers. One of these contains the above-mentioned albuminoid precipitate, which is lightened and made to float by the minute gas bubbles. Fermentation gives rise to these modifications in a progressive manner, and we have different stages or varieties of liefir, according to the time, lasting from one to three days. The acidity and the fluidity increase with the duration. Temperature and other conditions have a certain influence here. As to the dose, 10 to 20 fluid ounces per day is the average, and it should be taken slowly to have the best effect. It takes the place of other food, where this is necessary, but for many cases even as much as 40 fluid ances per day can be taken alon

The kefir can now be prepared on the spot by means of a substance in the form of powder, known as kefirogene. It is prepared in the laboratory and con tains the special agents of the kefiric fermentation in living state. This substance is not obtained from the dry grain of the kefir, but with a must of liefir culture in full activity. To produce the liefir, the powde is added to bottles of boiled milk provided with a patent stopper, and it causes a fermentation of the milk, giving rise to the product described above. From two to three days is the time required, and the tem perature is kept near 68 deg. F. during this time.

A similar product which has received considerable attention of late is known as yohourth. While the liefir comes from the Caucasus region, the latter product is taken from Bulgaria or the neighboring regions, where its use is general and its dietetic qualities recognized. While it has the same general properties, it differs from kefir in its consistence and taste, seeing 